\title{
nombalina
}

(8)

\section{A figura de Horácio}

Autor(es): $\quad$ Fernandes, Raul Miguel Rosado

Publicado por: Centro de Estudos Clássicos e Humanísticos; Imprensa da Universidade de Coimbra

URL

persistente: URI:http://hdl.handle.net/10316.2/32037

DOI: $\quad$ DOI:http://dx.doi.org/10.14195/978-989-8281-11-1_2

Accessed : $\quad$ 26-Apr-2023 15:31:09

A navegação consulta e descarregamento dos títulos inseridos nas Bibliotecas Digitais UC Digitalis, UC Pombalina e UC Impactum, pressupõem a aceitação plena e sem reservas dos Termos e Condições de Uso destas Bibliotecas Digitais, disponíveis em https://digitalis.uc.pt/pt-pt/termos.

Conforme exposto nos referidos Termos e Condições de Uso, o descarregamento de títulos de acesso restrito requer uma licença válida de autorização devendo o utilizador aceder ao(s) documento(s) a partir de um endereço de IP da instituição detentora da supramencionada licença.

Ao utilizador é apenas permitido o descarregamento para uso pessoal, pelo que o emprego do(s) título(s) descarregado(s) para outro fim, designadamente comercial, carece de autorização do respetivo autor ou editor da obra.

Na medida em que todas as obras da UC Digitalis se encontram protegidas pelo Código do Direito de Autor e Direitos Conexos e demais legislação aplicável, toda a cópia, parcial ou total, deste documento, nos casos em que é legalmente admitida, deverá conter ou fazer-se acompanhar por este aviso.

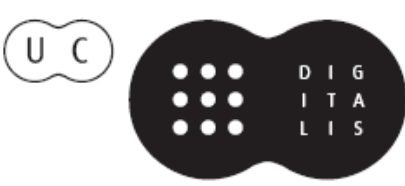




\section{Horácio \\ e a sua \\ Perenidade}

\section{Maria Helena Rocha Pereira, José Ribeiro Ferreira e Francisco de Oliveira}

IMPRENSA DA UNIVERSIDADE DE COIMBRA 


\section{A Figura de Horácio}

Raul Miguel Rosado Fernandes
Universidade de Lisboa

Fez-me a Comissão Organizadora descobrir a tempo (mas com pouco tempo para pensar) que o convite que há muitos meses me fora endereçado para falar de Horácio e da sua influência nas letras europeias se concretizava finalmente nesta sessão de Latinidade e que até me tinham marcado o tema para eu falar. O tema é este: "A figura de Horácio". À primeira vista, o status ambiguitatis consubstanciado na noção de "figura" intimidou-me, ao perguntarme o que queriam de mim. Acalmei-me e decidi em medida corajosa inverter o sentido do meu pensamento e perguntar-me a mim próprio "o que quero eu da figura de Horácio?”, cuja Arte Poética traduzi e comentei em tempos já imemoriais (nem quero dizer, por vaidade, há quantos anos), animado, além, disso, pelo pretexto ponderoso de me encontrar com todos os admiráveis e heróicos colegas que ainda hoje, no meio da ignorância generalizada do país e dos governantes, ousam impertinentemente estudar, traduzir e publicar, as letras clássicas, os textos medievais, a prosa e os poemas dos Humanistas. Alguns, os mais atrevidos, até persistem em ser versados in utraque lingua, ou seja, digamo-lo para os leigos, em Grego e Latim, que pouco contribuem para encontrar a melhor forma de combater qualquer deficit das contas públicas, ou para avaliar o Produto Interno Bruto, vulgo PIB, embora, e é isso que importa, nos informem e até com algum pormenor de situações parecidas, basta ler a história antiga, ligadas à riqueza e boa governança das nações, no rápido decorrer dos séculos. Tanto e tão pouco tempo, só porque o ser humano é o mesmo de sempre, dificilmente altera o seu comportamento, e só o tempo lhe foge. Eheu fugaces, Postume, Postume, / labuntur anni: "Ai, Ai, Póstumo, Póstumo, como os anos escorregam velozes”, é o próprio Horácio que o exclama, e é sobre a sua "figura" que vou falar. Abdicarei egoistamente de entrar em demasiados pormenores eruditos, que todos poderão encontrar na vastíssima bibliografia horaciana, desde esse admirável Dacier, crítico francês setecentista, aos nossos contemporâneos Kiessling-Heinze e Eduard Fraenkel, sem esquecer os três grossos volumes dedicados por Brink às composições poéticas, Epodos, Sátiras e Epistolas, consagradas à crítica literária. Recentemente, basta folhear o último volume da Année Philologique, referente às publicações de 2001, para vermos indicada a Enziclopedia Oraziana, iniciada por Della Corte, nas 7 páginas dedicadas a Horácio. É tanta a bibliografia, que, para evitar a nossa pretensiosa tendência filológica - que pode ser a morte da própria Filologia Clássica -, me vou limitar às minhas impressões pessoais sobre Horácio, numa visão em que procurarei integrá-lo, sem descer a centenas de citações, no porquê da sua contínua presença nas nossas conversas e nas obras de todos os tempos, mesmo na Idade da Trevas, tal mal compreendida e mal tratada por Petrarca. 
A figura de alguém, como ele, cuja obra teve influência na nossa sensibilidade e imaginação, não se limita a pormenores eruditos, nem à crítica textual dos escritos por essa personagem deixados, nem tão-pouco ao amálgama de opiniões expendidas durante séculos sobre esse "lindíssimo homenzinho", era assim que, brincando, lhe chamava o imperador Augusto, de baixa estatura e gordinho, conforme no-lo descreve Suetónio no curto passo biográfico que lhe dedica. Não é bem assim que o pintor Luigi Agricola desenha a sua efígie, seguindo a pintura de Rafael, numa gravura do século XVIII, que tenho diante da minha secretária, com a indicação de que nasceu "in Venosa, città del regno di Napoli”. Só que a fisionomia deve estar embelezada, com um magnífico perfil aquilino, cabeleira basta, ondulada e rodeada por uma coroa de louros.

À medida que o fui lendo, dei-me conta de que a pequena estatura física de que era dotado se ia avolumando, não só devido à beleza da poesia que nos deixou, como pela independência que manifestava perante os grandes deste mundo, ricos como Mecenas, poderosos como Augusto, ele que, filho de escravo forro, ou liberto, se quiserem, espécie de oficial de diligências que dirigia os leilões de bens penhorados, tivera a dita de que esse mesmo pai o retirasse da escola de Flávio onde dominavam os "meninos bem" da aristocracia da época, vestidos a rigor e de pesporrência inultrapassável, o acompanhasse a Roma para estudar, lhe custeasse os estudos, e finalmente o mandasse para Atenas, filosofar nos jardins de Academo, como qualquer pai mais elegante enviaria um filho seu de Lisboa para Paris ou Londres, a fim de que entrasse em contacto com o que de melhor havia no campo das artes e da literatura. Tratava-se de um rapaz provinciano de Venúsia, situada em pleno mezzogiorno italiano, na Apúlia, não muito longe da actual Bari. Os bens paternos resumiam-se a pouca coisa e a muito trabalho, o que não impediu o pai de ir procurar vida nova na capital do império.

A estada em Atenas não poderia resultar melhor quanto ao conhecimento que adquiriu das letras gregas, bem mais requintadas do que as do "agreste Lácio”, nem pior quanto aos contactos políticos que acabou por travar. Estava o jovem Horácio em Atenas, quando se deu conta da chegada triunfal de Bruto, o amigo de César, e depois seu exterminador, comparado pelos Atenienses aos tyrannoktónes que tinham livrado a cidade da tirania de Pisístrato e cuja estátua ainda lá se erguia. A admiração por Bruto, no exílio, ao exemplo do que sempre aconteceu na história do mundo antigo e moderno, vai ser partilhada pela juventude romana que estudava em Atenas, e nesse número figurará Horácio, que em defesa da liberdade republicana em breve se encontrará no campo de batalha, como tribunus militum, cargo para o qual Bruto carinhosamente o escolhera. Mas Bruto é derrotado e Horácio figurará na companhia dos vencidos e potenciais traidores da crescente e dominadora vontade imperial.

Daí a auto-ironia, que é uma das suas características que mais impressão exerce em quem não seja desprovido de sentido de humor, como é a frase consabida do relicta non bene parmula (Odes, II, 7, 10), "abandonando o escudo sem grande honra", com que comemora a fuga no meio da derrota de Filipos, lembrado por certo do tópos, que lera com certeza nos poemas de Arquíloco, 
onde o poeta-soldado desafia, para salvar a vida, a honra militar grega, que exigia aos guerreiros que trouxessem da batalha o seus escudos, ou que então viessem encaixados neles, isto é, mortos, mas com glória. É a personificação, por certo decadente, do anti-herói, que Horácio tentará atenuar compensando a negativa imagem, com o lema heróico imitado de um poema do espartano Tirteu, que ainda hoje a nossa escola militar arvora: Dulce et decorum est pro patria mori (Odes, III,2,13), "É doce e belo morrer pela pátria", o que hoje em dia não é fácil ser declamado pelos jovens que recusam o serviço militar obrigatório. Talvez, se a pátria estiver em perigo, talvez, talvez!!! Pode ser que a coragem ainda não seja um bem para sempre perdido!

Esta versatilidade nunca me impressionou desfavoravelmente nesse "estrangeirado filelénico", com profundas raízes romanas e provincianas, que é Horácio, pois apesar da sua admiração pela Hélade, acaba por desprezar o graeculus, o gregozinho do populacho, da plebecula, que já em Roma patriciamente tentava ignorar. Por ser desconcertante talvez, sem que por isso deixe de ser coerente e surpreendentemente corajoso. A verdade é que, mesmo a pedido de amigos influentes, sempre se recusou a escrever poesia épica, julgando que tal tarefa ser mais apropriada para as penas de Virgílio, "metade da sua alma", ou de Vário, mas nunca da sua, o que não obstou com a qualidade diplomática, mas firme, que todos lhe reconheceram, mesmo no seu tempo, a que elaborasse para as festas nacionais de Roma um solene Carmen saeculare, sabendo que era apreciado por Augusto que considerava tais composições como poemas que iriam permanecer para todo o sempre, mansura, na versão transmitida por Suetónio. Daí também o celebrar as vitórias e os sucessos políticos das grandes figuras de Roma, entre as quais, naturalmente, o imperador e o seu protector Mecenas, de origem real, conforme nos conta na ode, que todos fomos forçados a ler quando estudámos Latim. A maioria de nós não o estudou na adolescência por ser belo, não havia maturidade para tanto, mas sim por ser o poema introdutório e pedagogicamente obrigatório, da série de quatro livros, interrompidos entre os três primeiros e o quarto por outros afazeres literários do poeta, que, conforme ironicamente nos confessa, gostava de se levantar tarde. Bendito ócio que tão grande qualidade produziu! Mas esta exclamação só já adulto a proferi...

Precisamos todos de tempo, a menos que sejamos meninos-prodígio, para apreciarmos a alta qualidade; de tempo e de termos de comparação, e esses não faltam, sobretudo os de qualidade duvidosa, mas altamente premiados, em todas as épocas, não só na nossa, que conhecemos melhor. No final de contas para que servem os amigos? Como dizem os Ingleses, com o pragmatismo que caracteriza essa nação protestante, "you scratch my back and I'll scratch yours". Assim se ganham prémios, basta olharem à vossa volta lobrigando as mediocridades mais célebres, fillhas da mediatização do efémero.

Não é contudo com modéstia que Horácio avalia a sua obra, e há que dar-lhe razão, ela é mais duradoura do que o bronze: aere perennius, mas no entanto concede que é impossível imitar Píndaro, um poeta que bem estudou em Atenas e cuja influência é mais do que evidente em algumas das suas odes 
pindarizantes (desculpem o neologismo), como a I,12, em que celebra Augusto, mas que o leva a recusar utilizar o modelo proposto por um nobre romano, a fim de celebrar importantes vitórias romanas, por se considerar muito abaixo de Píndaro, que descreve com uma metáfora fantástica: "como um rio que se precipita de um monte e cujas margens conhecidas já foram inundadas pelas chuvas". As margens de Horácio, diz ele injustamente para consigo próprio, ainda conseguiam conter por defeito a inundação provocada pelas chuvas do talento. Será gongórico, mas nunca vi melhor forma de expressar o enthousiasmós poético, ou seja, o estar "possesso" pelo deus que inspira a poesia. É uma imagem com mais de dois milhares de anos, mas que ainda hoje me parece ter toda a pertinência. Que o digam os poetas do "absinto" do século XIX, ou os de outras drogas psicotrópicas do nosso século, pois também encontraram uma forma de se sentirem dominados por uma força que lhes é superior, mesmo que mortal!

Mas, se poetas que the são anteriores trouxeram para as letras latinas o hexâmetro dactílico (que varreu o verso satúrnio) e tantos outros metros, não menos verdade é que as líricas eólica e pindárica foram adaptadas à língua de Roma pelo esforço artístico de Horácio. Embora tenha mantido que é impossível aemulari Píndaro, não nega, antes o afirma sem rebuço na ode com que fecha os três livros, iniciais (III,30), que foi o primeiro (princeps) a trazer para Itália a poesia e os metros eólicos (de Safo e de Alceu) e pede a Melpómene, a suave Musa da Poesia, que por vontade própria lhe cinja a cabeleira com uma coroa de louro. Eis a gravura napolitana que costumo ter diante de mim.

Afinal este justo orgulho é o contraponto da aurea mediocritas aconselhada pelo poeta ao seu amigo Licínio, que sempre entendi como uma forma hábil de conduzir o quotidiano lidando moderadamente com os homens e de evitar a cólera dos deuses que castigam a insolência a býbris, muito embora o nosso anexim de "nem tanto ao mar nem tanto à terra" não esgote os matizes pretendidos pelo poeta. O que ele pretende, penso eu, é que na vida material não vale a pena procurar o mais luxuoso nem o mais caro, nem também aceitar masoquisticamente qualquer situação inferior, o que é sem dúvida, a definição de bom senso e bom gosto, não importa em que meio social ou intelectual, nem em que latitude geográfica. Corresponde afinal à tal filosofia de Epicuro, que é materialista sim mas contra a paixão excessiva, ao contrário do que pensam os que a confundem com o hedonismo.

Muito embora tenha conseguido, ao longo de vários anos, vencer as dificuldades métricas, sintácticas, semânticas e tudo o mais que Horácio nos oferece nas Odes, de ter saboreado com ele o locus amoenus da fonte de Bandúsia, o que sempre mais me impressionou foi a comunicação íntima que sempre mantém com o leitor, levando-o a pensar que o trivial do dia a dia afinal não é assim tão trivial, porque se trata da nossa vida delimitada no tempo, uma vez que todos estamos destinados a morrer e que essa mesma lívida Morte tanto bate com o pé (era o uso romano) nas barracas dos pobres como nas torres dos reis, e que a extrema brevidade da vida nos proíbe de iniciar uma 
esperança longa (Odes, I, 4). Isso não o impede, contudo, de odiar a populaça ordinária e dela se afastar (Odes, III, 1), visto que considera a sua poesia digna do aplauso de gente diferente. Este sentimento nada tem de demagógico e garante-nos que quem o pensa não anda à arreata do que o público lhe dita: leva tempo a compor uma obra e quer ser ele a escolher o género literário em que há-de cantar os poderosos, mesmo aqueles de quem depende. Essa a razão por que Augusto lhe faz saber que está furioso com ele, porque não lhe manda composição alguma que escreva, e de tal forma o sente que teme que a posteridade venha algum dia a pensar que ele tem vergonha de pertencer ao círculo de amigos da corte imperial. Horácio tem então a perícia de responder a Augusto na Epistola, II, 1 que só não o faz por não querer ir contra os interesses nacionais ao perturbar as tarefas de quem, como Augusto, tem sobre seus ombros e sozinho o peso de tantos assuntos políticos, de tantas leis a melhorar, e a obrigação de zelar pelos comportamentos da nação. E depois desta "amande honorable" oferece-lhe um pequeno ensaio, em verso bem entendido, sobre a criação literária contemporânea e arcaica, sem esquecer as comparações com os modelos gregos. É uma missiva admirável e actual.

Confesso que se compreende o motivo por que também Mecenas tudo lhe perdoa confessando-lhe que não o faria "se não gostasse de ti mais do que das minhas entranhas", conforme transcreve Suetónio, porque efectivamente é difícil encontrar alguém que consiga, sobretudo diante do poder absoluto, manter intacta a integridade da sua pessoa, sem sequer se dar ares de moralista ou de candidato a mártir, como já tantas vezes vimos no presente e no passado.

Não é pois por acaso que o vemos encetar novos caminhos como criticus (palavra importada do Grego na sua época) e litteratus (ou seja, grammatikós em Grego, cujo sentido era bem mais lato do que o de simples gramático) que disserta com humor e sarcasmo, com a língua acerada que nos dá a ideia correcta do que estamos a ler, quer seja uma peça antiga quer moderna. Assim fizessem alguns críticos actuais se evitassem "grelhas" que só nos confundem, ou crípticos juízos que nos fazem pensar num Aristóteles transvestido (não sei se a palavra existe, mas se não, passa existir) da crítica afrancesada e pedante. Não vejo maneira de encarar Lucílio, o predecessor satírico de Horácio em Roma, sem ir beber ao que dele diz o seu rival mais novo (Sátiras, I, 4): que segue o modelo dos autores da Comédia Antiga, mas que altera a métrica e o ritmo; que "embora com graça e de ventas assoadas, era contudo duro a escrever poesia"; o cúmulo porém era o escrever depressa demais, ao contrário do que Horácio pensava dever ser feito, e por isso "ditava versos com uma perna às costas" (ainda penso que é a melhor maneira de traduzir stans pede in uno) e daqui resultou que "como corre lamacento, coisas haverá que desejarias cortar". Pode-se acusar o crítico de Lucílio, que um arcaico sempre li com prazer, de ser perfeccionista, mas Horácio é perfeccionista e não vale a pena contrariá-lo.

De resto compensa-nos, e a mim também, com pequenas confidências de libertino, de solteirão, que segundo Suetónio tinha o quarto de cama repleto de espelhos para se ver nas poses amorosas, o que nos faz pensar que o "hard-core" erótico é efectivamente coisa velha, e como qualquer libertino já cansado, pede 
humildemente a Vénus (Odes, IV, 1), que o poupe, porque já não tem idade para se submeter aos seus caprichos: "Depois de teres parado tanto tempo, Vénus, vens de novo meter-me em guerras? Tem piedade peço-te, peço-te. Já não sou o mesmo que era no reino da velha Cinara. Desiste ó cruel mãe dos Amores, de dobrar quem já resistiu, cerca de cinco lustres, aos teus lascivos comandos; vai para onde te reclamam as doces preces dos jovens”. É um passo que veremos repetido praticamente como locus communis em muita da poesia ocidental e que resume o encontro indesejável, inexoravelmente humilhante, da paixão com a velhice para quem a paixão é mais uma ameaça do que um prazer.

É desta forma que lança a ponte entre ele o seu leitor. Comunicando-lhe, como se nada fosse, segredos íntimos, literários, políticos e outros. Pessoalmente sinto que por vezes entrelaça o seu braço no meu e me leva a visitar a Via Sacra em Roma, onde certa vez (Sátiras, I, 9), meditando em ninharias de que já nem se lembra, completamente por elas absorvido, é parado por um importuno, que mal conhece de nome, que lhe faz um interrogatório sobre o que faz, sobre o que não faz, tagarelando sobre as suas actividades e sobre os talentos que julga possuir, conversa que só encontra fim quando lhes aparece pela frente a parte contrária num pleito que o desastrado que tem a correr no tribunal. Quando, depois de conhecer o poema, dei por mim em Roma e na Via Sacra, como era possivel afastar da minha companhia o velho Horácio? Ele quase se tornou meu perseguidor, porque me forçou a seguir os passos dele próprio, que, há mais de dois mil anos, por ali andou, mas de facto fiquei a conhecer a Via Sacra, só que não era meu hábito passear, meditando, por ela ...

Andando acompanhado pela leitura dos seus poemas e das suas impressões é difícil não sentir a mesma insatisfação que o assalta no campo, na villa oferecida por Mecenas, e que o faz desejar voltar para a Urbe, onde a mesma frustração o torna saudoso do campo. Mas o poeta estava consciente desse fenómeno que os Românticos intitulavam de spleen e de tal maneira que na sátira dedicada a Mecenas (I,1) disserta sobre a insatisfação do ser humano, que nunca se contenta com a o tipo de vida que lhe cabe: "Ó felizes mercadores" diz o soldado já pesado nos anos e com os membros alquebrados por muitos trabalhos; por seu lado diz o mercador quando os ventos do Sul lhe abalam o navio: "a vida militar é melhor, e porquê? Porque se bate e num instante ou vem a morte rápida ou alegre vitória”. E o poeta conclui que tanto o soldado, como o mercador qui mare currunt unicamente procuram a segurança que lhes permita uma velhice sossegada, porque a verdade vai-nos revelar o poeta é que "os que atravessam os mares, de disposição não mudam" (Epistolas, 11, 27: non mutant animum, qui trans mare currunt). É esta ideia de correr para encontrar a felicidade que Horácio analisa com algum cepticismo, pois sabe que tal bem se não pode alcançar, ainda que citadino, vindo da província, pareça ter por instantes um lampejo optimista que o faz pensar que a felicidade reside na vida campestre, como no Epodo II em que leva o leitor a acreditar inocentemente que é "feliz aquele que longe das preocupações, como a antiga geração dos mortais, lavra com seus bois os campos deixados pelo pai, liberto de qualquer 
empréstimo", e assim por diante. E mergulha connosco nas delícias campesinas, para terminar mostrando que tal visão idílica era relatada por um agiota que recolhia o capital emprestado no meio do mês, para pensar investi-lo no princípio do mês seguinte.

É desconcertante seguir Horácio em todas a variações de que é capaz. Nelas se misturam decepções, desejos, conhecimentos, ambições, mas tudo aparece num todo congruente sem que se façam sentir dissonâncias, e consegue assim comunicar com enorme intimidade com cada um de nós, acompanhando-nos nos nossos afazeres, consolando-nos nas nossas preocupações e abrindo-nos horizontes que ainda hoje nos fazem apreciar a subtileza de pensamento de um homem culto e requintado.

Todos nos lembramos do célebre passo da Epístola a Augusto (II, 1, 156-7) em que com grande simplicidade Horácio confessa que "a Grécia conquistada, o feroz vencedor conquistou, pois trouxe as artes para o agreste Lácio.” É um fenómeno político e cultural que se verificou através dos tempos e que lembra um pouco o tópos do "caçador caçado", que não raro aparece em várias formas literárias. Podemos verificar esse fenómeno, ao longo da história, na romanização das tribos godas, na helenização dos árabes que destruíram a Biblioteca de Alexandria e depois conservaram textos gregos que de outro modo nunca teriam chegado por via da barbárie às nossas mãos, ou em tempos bem mais recentes a vitória dos Americanos sobre os Alemães que não só lhes trouxeram homens com Werner von Braun, como muitos outros por motivos indirectos, como Einstein, ou o filólogo clássico Kurt von Fritz, o mesmo acontecendo com os Ingleses que tiveram a sorte de acolher judeus fugitivos como Victor Ehrenberg, Eduard e Herman Fränkel e o católico Rudof Pfeiffer, que tanto nos ensinaram.

É fácil imaginar a influência da obra horaciana através dos séculos, passando pela Idade Média até aos nossos dias. Em Portugal fez-se ela sentir abertamente sobretudo desde o século XVI com António Ferreira, Sá de Miranda e outros. Fechados sobre nós próprios fez-se imitação de Horácio, e atrevo-me a dizer sem a originalidade que ele próprio para si exigia no que respeitava os seus modelos gregos, pois considerava os imitadores sem imaginação, como "gado servil" e simiesco. A liberdade de pensamento horaciana não era assim tão apreciada, era tolerada, e basta lermos o seu admirador e imitador Cândido Lusitano para nos apercebermos dessa limitada tolerância. Na Arte Poética ou Regras da Verdadeira Poesia, Lisboa, 1748, p.380 segs, apesar de solenemente o apelidar de Píndaro da Itália, remata (p.382): "Assim este Poeta fosse tão digno de se imitar no que respeita aos costumes, porque muitas vezes como verdadeiro Epicureo, que era, se deixava arrastar todo dos seus gostos, e usava de sentimentos, e expressoens bem pouco modestas". Essa mesma liberdade de expressão e de pensamento demonstrada pelo poeta não era partilhada por todos os grandes espíritos antigos e referimo-nos ao tema da Sátira,I, 4, que enumera três nomes de poetas da Comédia Antiga, Êpolis, Cratino e Aristófanes, realçando a muita liberdade com que apontavam para quem fosse digno de ser descrito, por ser mau ou ladrão, por ser adúltero ou assassino, ou 
por ser famoso por qualquer outro motivo. $\mathrm{E}$ assim era de facto, como aponta o próprio poeta na Arte Poética, 281, que explica o desaparecimento da Comédia Antiga pelos abusos por ela cometidos, não referindo a razão principal que residia no facto da classe política e os grandes de Atenas não quererem ser alvo de chacota. Já Cícero no De republica, 4, 11, mostra-se um pouco molestado pela crítica dos autores cómicos dizendo: (Comoedia Graeca) populares homines improbos, in re publica seditiosos, Cleonem, Cleophontem, Hyperbolum laesit. Patiamur, etsi eius modi ciues a censore melius est quam a poeta notari, o que em vernáculo significa: "A comédia grega veio ferir homens conhecidos por serem desonestos, traidores da república, como Cleonte, Cleofonte, Hipérbolo. Admitamo-lo, muito embora seja melhor que cidadãos dessa laia sejam apontados por um censor do que por um poeta”. É uma crítica discreta do jurisconsulto e possivelmente uma forma de corporativamente evitar tamanho perigo. A comédia seria a comunicação social da época, certamente mais bem escrita do que a que lemos, e certamente, ontem e hoje, como sabemos, com má ou boa intenção, pode constituir um obstáculo à corrupção da sociedade, o que nem a todos agrada.

Felizmente que não devia ser essa a opinião de Fernando Pessoa, que a meu ver foi o único que conseguiu pela mão de Ricardo Reis "reescrever" Horácio, sem lhe ficar muito a dever. Pena é que O Ano da Morte de Ricardo Reis, não conseguisse obter o mesmo resultado e nos leve a pensar por que razão é Ricardo Reis concebido tão fora da graça e perícia que lhe deu origem, sobrecarregado que está com um soturno livro de 400 páginas. De Horácio há de facto bem pouco, de Ricardo Reis tropical, pois é brasileiro, não muito, o que é francamente pena.

Antes de terminar esta fala no dia da Latinidade, queria lembrar o que disse no início acerca dos que ainda mantêm vivas as nossas raízes culturais ligadas literária e politicamente ao mundo antigo. Se me coubesse a mim escolher um premiado para esse dia, seria o grupo de classicistas que obteria o prémio, porque mal pagos, mal amados, e pouco compreendidos devido à douta ignorância das gentes, continuam imperturbáveis, e independentes da crescente partidarização da cultura, a criar uma verdadeira renascença de livros, de estudos e de edições, da época clássica, da Idade Média, do Humanismo, e de tudo o que sobre a antiguidade a nós chegou. Essa a razão por que foi com muita honra que aqui falei, e é com o sentimento do dever cumprido que de todos me despeço. 